\title{
Pai contemporâneo: Diálogos entre pesquisadores brasileiros no período de 1998 a 2008
}

\author{
The contemporaneous father: Dialogues among \\ Brazilian researchers from 1998 to 2008
}

\begin{abstract}
Aline Grazieli de Oliveira ${ }^{[a]}$ Rosanna Rita Silva ${ }^{[b]}$
[a] Acadêmica do curso de Psicologia da Universidade Estadual do Centro-Oeste, UNICENTRO, participante do Programa de Iniciação Científica, Irati, PR - Brasil, e-mail: alinegrazielipr@yahoo.com.br

${ }^{[b]}$ Docente do Departamento de Psicologia da Universidade Estadual do Centro-Oeste, (UNICENTRO), Guarapuava, PR - Brasil, e-mail: rosanna@irati.unicentro.br
\end{abstract}

\section{Resumo}

A paternidade implica uma experiência complexa - quando exercida em um tempo em que seu lugar e suas atribuições não se mostram tão claramente, transforma-se em vivência ainda mais inquietante. Diante disso, o presente trabalho surge com a proposta de discutir como a paternidade está sendo compreendida na contemporaneidade pelas ciências humanas e da saúde no Brasil. Assim, foi realizada uma revisão de literatura com a utilização das publicações disponíveis na base de dados Scientific Electronic Library Online, SciELO, a partir da qual procurou-se estabelecer um diálogo entre os vários autores que trataram da questão no período compreendido entre 1998 e 2008 no País, abrindo perspectivas diversas para a pesquisa e reflexões teóricas. Dessa forma, identificou-se que a concepção de paternidade passa por transformações que resultam em uma forma de ser pai mais sensível e participante. Nessa nova paternidade, amplia-se a possibilidade de efetivo envolvimento com o filho e, a partir disso, a possibilidade de construir-se enquanto sujeito. No entanto, deve-se mencionar que exigências anteriores ainda fazem parte da nova paternidade. O ser pai atualmente engloba rupturas e continuidades com o modelo tradicional, o que permite que as duas formas de exercê-lo possam estar presentes ao mesmo tempo. Desse modo, pode-se dizer que a paternidade contemporânea exige uma reinvenção do caminho que um pai deve trilhar.

Palavras-chave: Paternidade. Relações pais-criança. Psicologia do homem. 


\begin{abstract}
Fatherhood constitutes a complex experience - when practiced in a period in which its role and duties are not clearly defined, it becomes an even more disturbing existence. This work, therefore, intends to propose a discussion about the way fatherhood has been seen presently by the human and health sciences in Brazil. Thus, a literary review was accomplished based on the available issues of the Scientific Electronic Library Online database (SciELO), from which an attempt to establish a dialogue among the several authors who approached the subject from 1998 to 2008 in our country was done, revealing new perspectives for research and theoretical reflections. As a result, it was possible to ascertain that the concept of fatherhood goes through changes that lead to a way of being a more sensitive and sharing father. In this new concept of fatherhood, the possibility of an effective involvement between father and child is enlarged and, from then on, a chance to construct himself as a new individual. However, it must be mentioned that the previous demands are still part of the new fatherhood. The condition of being a father, nowadays, comprises ruptures and continuities in relation to the traditional model, which allows both ways to coexist. Hence, it can be stated that contemporaneous fatherhood demands a reinvention of the path a father must track.
\end{abstract}

Keywords: Fatherhood. Father-child relationships. Men's Psychology.

\title{
Introduçáo
}

A paternidade por si só já corresponde a um período de transformações na vida de um homem - porém, quando exercida num tempo em que as funções atribuídas ao pai parecem não estar tão bem delineadas como em épocas anteriores, pode se tornar ainda mais inquietante.

Em paralelo com grandes avanços tecnológicos no campo da reprodução humana e a maior expressividade da mulherem todos os âmbitos, pode-se dizer que a própria concepção de paternidade passa por importantes mudanças.

Antes, cabia ao pai a função de chefiar a sua família, zelando sempre pelo seu sustento. Os seus deveres estavam preestabelecidos por gerações anteriores e havia poucas possibilidades de exercê-los de outras formas. Uma das razões que o colocava nesse campo reside no fato de que o homem era a única pessoa que trabalhava fora de casa. A mulher, por sua vez, permanecia no lar, responsabilizando-se pela criação do filho e ocupando o lugar central no desenvolvimento afetivo da criança (MeunierCastelain, 1993).

Algumas tarefas exigidas anteriormente não perderam o seu valor, como é o caso do sustento da família. No entanto, outras funções foram acrescentadas, como a aproximação afetiva e o diálogo. Ao ser chamado em sua própria casa, o homem teve a possibilidade de ampliar o contato com seus filhos e a participar mais no processo formativo. Além disso, aquele pai autoritário deu lugar a um pai mais flexível e sensível às diversas situações cotidianas.

Pode-se dizer que dentro da nova perspectiva de paternidade, o homem se constrói enquanto pai na sua relação com o filho. À medida que convivem, trocam experiências, aprendem coisas novas e abandonam opiniões já formadas. Como ressalta Montgomery (1998), o pai de agora aceita que a relação afetiva com seu filho seja uma forma de desenvolvimento para si, do mesmo modo que aceita vivenciar, juntamente com ele, seus anseios.

A partir da ideia de transformação da paternidade é que o presente estudo surgiu como uma possibilidade de discutir, por meio de uma revisão de literatura, como a paternidade está sendo compreendida na contemporaneidade pelas ciências humanas e da saúde no Brasil. A proposta é a de estabelecer um diálogo entre os vários autores que trataram da questão no período compreendido entre 1998 e 2008 no País, abrindo perspectivas diversas à pesquisa e às reflexões teóricas.

\section{Metodologia}

O estudo foi realizado por meio de uma revisão de literatura com a utilização das publicações disponíveis na base de dados Scientific Electronic 
Library Online (SciELO). Foram utilizados os seguintes descritores: paternidade, papéis dos pais e função paterna.

Os critérios de inclusão foram artigos que discutiam a temática da paternidade na idade adulta, produzidos no Brasil, em língua portuguesa e publicados no período de 1998 a 2008, disponíveis por meio dessa base de dados.

Foram excluídos estudos que tratavam da paternidade na adolescência em razão do entendimento de que demandariam uma discussão particularizada.

Percorrendo a trajetória descrita, foram encontrados 131 artigos, sendo 93 para o descritor paternidade, 24 para papéis dospais e 14 para função paterna. Em seguida, foi realizada uma seleção mais detalhada a partir da leitura dos resumos de todos os trabalhos, com base nos critérios de inclusão e de exclusão propostos no estudo. Tal análise resultou em 26 artigos que foram efetivamente pesquisados, sendo 23 para o descritor paternidade, 1 para papéis dos pais e 2 para função paterna.

Os artigos estudados apresentam, predominantemente, pesquisas com a utilização de abordagem qualitativa, seguidos pelas produções teóricas. Esses estudos, que tratam do pai ou que pelo menos descrevem suas especificidades, começam a crescer a partir de 2004 na literatura das ciências humanas e da saúde no Brasil. Em 1998, 2000 e 2001 não foi encontrada produção nesse sentido; nos anos de 1999, 2003 e 2008 há um trabalho publicado em cada ano e, em 2002, três. A partir de 2004 até 2007 foram identificadas cinco publicações anuais.

Assim, desse total de 26 produções é que se articula uma visão da paternidade contemporânea, estabelecendo pontes de interlocução entre os diversos autores e os textos produzidos no período.

\section{Tecendo diálogo entre os autores}

A paternidade pode ser entendida como um significante decisivo na construção da identidade do sujeito (Rosa, 2008), pois promove transformações na vida conjugal e na forma de se relacionar com o mundo. Além disso, é fundamental para a construção da identidade do filho, na medida em que lhe serve de referência.

Para Bustamante (2005), a paternidade é uma experiência que se constrói em vários níveis socioculturais ou relacionais - o modo como os outros a veem, além do relacionamento com a mãe do seu filho, exercem grande influência sobre a forma como será vivida. Por outro lado, as experiências anteriores também estão em jogo na construção dessa vivência, e a forma com que serão utilizadas no momento atual depende da singularidade de cada homem.

Além disso, esta não é uma vivência estática, visto que a própria concepção de paternidade sofre modificações ao longo do tempo. Para Gomes e Resende (2004), o pai, antes considerado somente o provedor do sustento do filho, começa a ser chamado para exercer mais ativamente suas funções. Com isso, o modelo de família tradicional, no qual o pai é o nível mais alto de hierarquia dá lugar a um pai mais íntimo e sensível (Gomes \& Resende, 2004).

Diversos autores (Andrade, Costa \& Rossetti-Ferreira, 2006; Bustamante, 2005; Gomes \& Resende, 2004; Hennigen \& Guareschi, 2002; Silva \& Piccinini, 2007; Tarnowski, Próspero \& Elsen, 2005; Wagner, Predebon, Mosmann \& Verza, 2005) apontam o movimento feminista e a ascensão da mulher ao mercado de trabalho como marco inicial da nova configuração da paternidade. O movimento feminista da década de 1960 provocou mudanças nas condições femininas e masculinas (Braga \& Amazonas, 2005; Tarnowski et al., 2005), o que impulsionou a criação de novas possibilidades de ser pai.

Gomes e Resende (2004) acreditam que o envolvimento afetivo é o diferencial do pai contemporâneo. Não se trata simplesmente de adotar atitudes contrárias às exercidas pelo pai tradicional, mas de aceitar os sentimentos e a ambivalência evocados por essa relação.

Em relação ao pai tradicional, podem-se apontar como principais características o distanciamento afetivo, o papel de provedor da família e o poder que exercia sobre os demais membros (Gomes \& Resende, 2004). Freitas, Coelho e Silva (2007) verificaram em seus estudos que os pais cujo posicionamento se aproxima mais do modelo tradicional entendem que a paternidade se inicia com o nascimento da criança. Ao fazer isso, esses homens distanciam-se de suas companheiras durante toda a gestação. Por outro lado, os pais que se aproximam da nova concepção veem a gravidez como o início da paternidade, envolvendo-se emocionalmente antes mesmo de o filho nascer.

O homem foi sentindo necessidade de expressar seus sentimentos de forma mais ampla e, paralelamente, a sua participação na vida do filho 
passou a ser valorizada. Antes estava a cobrança de um provedor autoritário; agora se valoriza a participação e o envolvimento com o filho (Dantas, Jablonski \& Féres-Carneiro, 2004).

O pai contemporâneo é aquele que deseja romper com o modelo da família de origem. E o faz a partir da demonstração de suas emoções e de sua participação nas atividades cotidianas do filho, sentindo-se na maioria das vezes, satisfeito por isso (Andrade et al., 2006).

Essa visão de paternidade está relacionada à criação e não mais apenas à concepção, e diz respeito à forma como os pais criam e educam o filho. No entanto, por mais que uma nova configuração esteja sendo construída, proporcionar o sustento ainda é a principal tarefa de um pai (Bustamante, 2005; Costa, 2002) - tarefa essa que os sujeitos da pesquisa de Bornholdt, Wagner e Staudt (2007) evidenciam como um dever imposto pela sociedade por gerações e gerações anteriores.

Pereira e Silva (2006) expõem que, no meio judicial, além da responsabilidade de prover o sustento, instalam-se com mais intensidade aspectos vinculados ao relacionamento afetivo. Esse fato permite, por exemplo, que um filho cobre indenizações por não ter sido amado durante todo seu desenvolvimento, particularmente na infância.

Outro fato que pode ser inserido nessa discussão é a necessidade evidenciada por alguns homens que, mesmo depois de terem criado seus filhos, pedem um exame de paternidade genética (Fonseca, 2004; Fonseca, 2005). Isso pode ser visto nos dois estudos em que a autora encontrou diversos homens que, após a separação conjugal, sentiram a necessidade de comprovar a paternidade biológica dessas crianças que criaram. Tal ação mostra que por mais que a convivência com elas esteja relacionada com a paternidade, o laço biológico, ou seja, a concepção ainda é muito valorizada individual e coletivamente.

Fonseca (2005) acrescenta que da mesma forma que o vínculo sanguíneo conta para a aceitação e reconhecimento de um filho, há homens que assumem o status paterno sem relação com os aspectos genéticos. Desse modo, a autora aponta para o fato de que a biologia não é o fundamento único da paternidade, pelo menos não do ponto de vista dos homens porém, pode revelar e influenciar comportamentos.

Ao assumir a paternidade, o homem aceita a responsabilidade de zelar pela vida de uma criança, seja esse pai biológico ou não (Pereira \& Silva, 2006). Atualmente existem várias possibilidades de exercer a paternidade, seja pelo nascimento de um filho (Bornholdt et al., 2007; Bustamante, 2005; Silva \& Piccinini, 2007); pela reprodução assistida (Braga \& Amazonas, 2005; Borlot \& Trindade, 2004; Corrêa \& Loyola, 1999); pela adoção de bebês e crianças (Andrade et al., 2006; Schettini, Amazonas \& Dias, 2006); pela adoção tardia (Costa \& Rossetti-Ferreira, 2007); a partir da separação conjugal (Dantas et al., 2004; Perucchi \& Beirão, 2007); ou a partir do casamento com pessoas que já têm filhos.

Há a possibilidade de se ter um filho quando o homem é adolescente, adulto e quando se encontra na terceira idade. Também há a possibilidade de participar ativamente da gestação, do nascimento (Carvalho, 2003) e de todo seu processo de desenvolvimento, além de construir uma relação com um filho que já se conhece adolescente, por exemplo. Todas elas proporcionam para as pessoas envolvidas novas experiências, carregadas de sentimentos contraditórios, muitas dúvidas e ambivalências (Braga \& Amazonas, 2005; Farinati, Rigoni \& Müller, 2006; Freitas et al., 2007; Schettini et al., 2006). Cada uma dessas possibilidades possui suas peculiaridades, mas todas implicam uma vivência marcante que exige readaptações, seja na vida emocional, conjugal ou econômica (Bornholdt et al., 2007; Bustamante, 2005; Costa \& Rossetti-Ferrreira, 2007).

Isso pode ser compreendido pelo fato de que todas essas vivências que o ser pai envolve requerem tempo para aceitação de mudanças (Freitas et al., 2007; Tarnowski et al., 2005), bem como para a elaboração de fantasias e sentimentos decorrentes da sua própria infância (Piccinini, Silva, Gonçalves, Lopes \& Tudge, 2004) e, particularmente, das suas experiências com seu próprio pai (Freitas et al., 2007; Silva \& Piccinini, 2007).

Gomes e Resende (2004) também discutem que o nascimento de um filho pode ser discutido no contexto da transgeracionalidade, pois atualiza no homem conflitos em relação ao seu pai, de forma que, ao sentirem seus pais como distantes, por exemplo, desejem se tornar pais diferentes. Para esses autores, então, é no cerne dos sentimentos paternos de cada homem e na rede de relações estabelecidas com o pai real ou imaginário é que se tornam possíveis a construção e reconstrução da sua subjetividade de pai.

Outro aspecto relevante diz respeito à lentidão com que as mudanças no modo de conceber a 
paternidade acontecem. Alguns autores (Dantas et al., 2004; Freitas et al., 2007; Gomes \& Resende, 2004; Perucchi \& Beirão, 2007; Thurler, 2006) afirmam que, por não ser algo linear, a construção da nova concepção de pai envolve rupturas e continuidades com o modelo tradicional, o que faz com que as duas formas de vivenciar a paternidade estejam presentes ao mesmo tempo. Além disso, segundo Tarnowski et al. (2005), a nova forma de pensar a paternidade e como ela deve ser exercida, além de provocar sentimentos ambivalentes nos pais, gera insegurança em relação ao modelo que devem cumprir.

Bornholdt et al. (2007) assinalam que ser pai atualmente é como caminhar em um terreno desconhecido, em que as referências passadas não conseguem suprir as exigências atuais, o que traz a necessidade de reinventar e redefinir o seu lugar na família e na sociedade.

Essas mudanças, que ampliam a visão de paternidade e que instigam os estudiosos acerca da temática, ainda não recebem atenção semelhante à dirigida para a maternidade (Bustamante, 2005; Paiva, Lima, Santos, Ventura-Filipe \& Segurado, 2002). No entanto, com a ampla inserção da mulher no mercado de trabalho (Tarnowski et al., 2005), com os movimentos feministas e com as separações conjugais (Tarnowski et al., 2005), a importância da paternidade para o desenvolvimento da criança começou a ser melhor identificada.

Freitas et al. (2007) também apontam em seu trabalho que o pai é esquecido, de maneira que ainda não é amplamente compreendido e abordado no campo científico. Sugerem, então, que se investiguem principalmente aspectos subjetivos de futuros pais, como suas expectativas, sentimentos, percepções e vivências.

Por outro lado, Tarnowski et al. (2005) afirmam que o envolvimento paterno é mais complexo do que se imagina mas, mesmo assim, continua sendo excluído nos programas de saúde. Para esses autores, há frequentemente uma feminilização desses serviços, fato esse que promove o afastamento do pai.

Diante de tudo isso, parece claro que é necessário aprofundar todas essas discussões, primeiramente para a compreensão dos aspectos que envolvem o homem neste momento e, posteriormente, para que ele seja inserido efetivamente e estimulado com maior intensidade a vivenciar a paternidade nos seus múltiplos aspectos, possibilidades e contextos sociais.

\section{Fazendo consideraçóes finais e novas propostas}

Este estudo identificou que especificidades da paternidade começam a ser mais inseridas na literatura científica brasileira a partir do ano de 2004. Antes desse período, o pai também fazia parte do interesse de pesquisadores, porém como coadjuvante no processo de desenvolvimento da criança, que era antes visto como centrado na relação mãe-criança.

Estudar o pai não significa desqualificar a inserção da mãe nesse processo. A maternidade e a paternidade consistem em vivências diferenciadas e assim podem e devem ser tratadas. Constituem-se momentos de grandes transformações na vida da mulher e do homem, de forma que, ao vivenciá-los, eles podem reconstruir-se enquanto sujeitos. Longe de constituírem-se em experiências estáticas, a maternidade e a paternidade passam por constantes reestruturações, com múltiplos determinantes e, sobretudo, interagindo mutuamente nas configurações que apresentam em cada momento histórico.

Ser pai atualmente não é uma tarefa fácil talvez nunca tenha sido. No entanto, no contexto sociocultural e econômico contemporâneo, que dá origem a uma ampla diversidade de constelações familiares e a diferentes dinâmicas relacionais entre seus membros, os desafios de transformação se colocam de maneira premente.

Para Meunier-Castelain (1993), o chefe de família tradicional usufruía de uma paternidade estável e coerente na sua própria perspectiva, em que as funções que deveriam ser desempenhadas estavam bem delineadas. Agora, no entanto, em meio às incertezas e à ampliação das possibilidades de atuação, o homem pode não saber como ocupar seu espaço junto aos filhos e demais membros da família. O autor expõe ainda que a redefinição das funções que um pai precisa desempenhar acaba por abalar os seus pontos de referência, criando assim a necessidade de experimentar.

Do homem agora são exigidas ações que antes pareciam ser cobradas exclusivamente das mulheres, como envolver-se emocionalmente com o filho e participar ativamente de sua vida. Entretanto, não se pode esquecer que, apesar de exigir uma conduta mais afetuosa com o filho, proporcionar o seu sustento ainda é tarefa de um pai e seu longo aprendizado histórico deu-se nesse sentido. 
O percurso de inserção em novos tempos e novas exigências ocorre de forma lenta e gradual, o que permite identificar que as duas paternidades, tradicional e contemporânea, são exercidas simultaneamente - tanto no mesmo tempo e no mesmo lugar por homens diferentes como em diferentes momentos e lugares pelo mesmo homem, na busca de melhor cumprir o que supõem ser o essencial ao desenvolvimento dos filhos.

A forma como cada homem reage diante da paternidade potencial e/ou vivencial pode ser entendida a partir de sua organização psíquica e dos inúmeros determinantes socioculturais, econômicos e históricos, o que indica que cada um possui um modo singular de ser, com potencialidades e limitações particulares. No entanto, sejam quais forem as alternativas encontradas contemporaneamente, é de fundamental importância que todo homem tenha espaço e acolhimento para expressar suas inquietações e angústias e, ainda, compartilhá-las.

Para que isso seja possível, é necessário que a temática da paternidade deste início de século seja aprofundada, possibilitando avanços na compreensão da questão em toda sua complexidade.

Cabe finalmente ressaltar que o presente estudo consiste em uma das várias possibilidades de diálogo entre os diversos autores citados, não excluindo-ao contrário, encorajando-outras formas possíveis de articulação dessa produção teórica, cuja pertinência histórica merece ser evidenciada.

\section{Referências}

Andrade, R. P., Costa, N. R. A., \& Rossetti-Ferreira, M. C. (2006). Significações de paternidade adotiva: Um estudo de caso. Paidéia, 16(34). Recuperado em 3 set. 2009, em http://www.scielo.br/scielo. php? script $=$ sci_arttext\&pid $=$ S0103-863X2006000 200012\&lng $=$ pt\&nrm $=$ iso

Braga, M. G. R., \& Amazonas, M. C. L. A. (2005). Família: Maternidade e procriação assistida. Psicologia em Estudo, 10(1). Recuperado em 3 set. 2009, em http://www.scielo.br/scielo.php?script $=$ sci_ arttext\&pid=S1413-73722005000100003\&lng $=$ pt \&nrm $=$ iso
Borlot, A. M. M., \& Trindade, Z. A. (2004). As tecnologias de reprodução assistida e as representações sociais de filho biológico. Estudos de Psicologia, 9(1). Recuperado em 3 set. 2009, em http:/ /www.scielo.br/ scielo.php?script $=$ sci_arttext\&pid=S1413-294X200 $4000100008 \& \operatorname{lng}=\mathrm{pt} \& \mathrm{nrm}=$ iso

Bornholdt, E. A., Wagner, A., \& Staudt, A. C. P. (2007). A vivência da gravidez do primeiro filho à luz da perspectiva paterna. Psicologia Clínica, 19(1). Recuperado em 18 ago. 2009, em http://www.scielo.br/scielo.php? script=sci_ arttext\&pid $=$ S0103-56652007000100006\&lng $=$ pt $\&$ nrm $=$ iso

Bustamante, V. (2005). Ser pai no subúrbio ferroviário de Salvador: Um estudo de caso com homens de camadas populares. Psicologia em Estudo, 10(3), 393-402. Recuperado em 3 set. 2009, em http://www.scielo.br/scielo.php? script $=$ sci_ arttext\&pid $=$ S1413-73722005000300007\&lng $=$ pt $\&$ nrm $=$ iso

Carvalho, M. L. M. (2003). Participação dos pais no nascimento em maternidade pública: Dificuldades institucionais e motivações dos casais. Cadernos de Saúde Pública, 19(suppl. 2). Recuperado em 3 set. 2009, em http://www.scielo.br/scielo. php? script $=$ sci_arttext\&pid $=$ S0102-311X2003000 800020\&lng $=$ pt\&nrm $=$ iso

Corrêa, M. V., \& Loyola, M. A. (1999). Novas tecnologias reprodutivas: novas estratégias de reprodução? Physis: Revista Saúde Coletiva, 9(1). Recuperado em 3 set. 2009, em http://www.scielo.br/pdf/physis/ v9n1/09.pdf

Costa, R. G. (2002). Reprodução e gênero: Masculinidades e teorias da concepção. Revista Estudos Feministas, 10(2). Recuperado em 3 set. 2009, em http://www.scielo.br/scielo.php?script=sci_ arttext\&pid $=$ S0104-026X2002000200005\&lng $=p t$ $\& n r m=$ iso

Costa, N. R.A., \& Rossetti-Ferreira, M. C. (2007). Tornar-se paiemãeemumprocessode adoçãotardia. Psicologia: Reflexão e Crítica, 20(3). Recuperado em 7 set. 2009, em http://www.scielo.br/scielo.php? script $=$ sci_ arttext\&pid $=$ S0102-79722007000300010\&lng $=$ pt $\&$ nrm $=$ iso 
Dantas, C., Jablonski, B., \& Féres-Carneiro, T. (2004). Paternidade: Considerações sobre a relação paisfilhos após a separação conjugal. Paidéia, 14(29). Recuperado em 3 set. 2009, em http:/ /www.scielo.br/ scielo.php?script $=$ sci_arttext\&pid $=$ S0103-863X200 4000300010\&lng $=$ pt\&nrm $=$ iso

Farinati, D. M., Rigoni, M. S., \& Müller M. C. (2006). Infertilidade: Um novo campo da psicologia da saúde. Estudos de Psicologia, 23(4). Recuperado em 3 set. 2009, em http://www.scielo.br/scielo. php? script $=$ sci_arttext\&pid $=$ S0103-166X2006000 400011\&lng $=$ pt\&nrm $=$ iso

Fonseca,C. (2004). A certeza quepariua dúvida:Paternidade e DNA. Revista Estudos Feministas, 12(2). Recuperado em 3 set. 2009, em http:/ / www.scielo.br/ scielo.php?script $=$ sci_arttext\&pid $=$ S0104-026X200 4000200002\&lng $=$ pt\&nrm $=$ iso

Fonseca, C. (2005). Paternidade brasileira na era do DNA: A certeza que pariu a dúvida. Cuadernos de Antropología Social, 22. Recuperado em 3 set. 2009, em http://www.scielo.br/pdf/ref/ v12n2/23958.pdf

Freitas, W. M. F., Coelho, E. A. C., \& Silva, A. T. M. C. (2007). Sentir-se pai: A vivência masculina sob o olhar de gênero. Cadernos de Saúde Pública, 23(1). Recuperado em 3 set. 2009, em http:/ / www.scielo.br/ scielo.php? script $=$ sci_arttext\&pid=S0102-311X200 7000100015\&lng $=$ pt\&nrm $=$ iso

Gomes, A. J. S., \& Resende, V. R. (2004). O pai presente: o desvelar da paternidade em uma família contemporânea. Psicologia: Teoria e Pesquisa, 20(2), 119-125. Recuperado em 3 set. 2009, em http://www.scielo.br/scielo.php?script $=$ sci_ arttext\&pid $=$ S0102-37722004000200004\&lng $=$ pt \&nrm $=$ iso

Hennigen, I., \& Guareschi, N. M. F. (2002). A paternidade na contemporaneidade: Um estudo de mídia sob a perspectiva dos Estudos Culturais. Psicologia \& Sociedade, 14(1). Recuperado em 3 set. 2009, em http://www.scielo.br/scielo.php?script $=$ sci_ arttext\&pid=S0102-71822002000100004\&lng $=$ pt $\& \mathrm{nrm}=$ iso

Meunier-Castelain, C. (1993). Fiquem ligados, papais! Os homens diante da mulher e dos filhos. São Paulo: Summus.
Montgomery, M. O novo pai. São Paulo: Gente, 1998.

Paiva, V., Lima, T. N., Santos, N., Ventura-Filipe, E., \& Segurado, A. (2002). Sem direitos de amar? A vontade de ter filhos entre homens (e mulheres) vivendo com o HIV. Psicologia USP, 13(2). Recuperado em 3 set. 2009, em http://www.scielo.br/scielo.php?script=sci_ arttext\&pid $=$ S0103-65642002000200007\&lng $=$ pt\& $\mathrm{nrm}=$ iso

Pereira, R. C., \& Silva, C. M. (2006). Nem só de pão vive o homem. Sociedade e Estado, 21(3). Recuperado em 3 set. 2009, em http://www.scielo.br/scielo.php?script=sci_ arttext\&pid=S0102-69922006000300006\&lng $=$ pt\&nr $\mathrm{m}=$ iso

Perucchi, J., \& Beirão, A. M. (2007). Novos arranjos familiares: Paternidade, parentalidade e relações de gênero sob o olhar de mulheres chefes de família. Psicologia Clínica, 19(2). Recuperado em 3 set. 2009, em http://www.scielo.br/scielo.php? script $=$ sci_ arttext\&pid $=$ S0103-56652007000200005\&lng $=$ pt \&nrm $=$ iso

Piccinini, C. A., Silva, M. R., Gonçalves, T. R., Lopes, R. S., \& Tudge, J. (2004). O envolvimento paterno durante a gestação. Psicologia: Reflexão e Crítica, 17(3). Recuperado em 3 set. 2009, em http://www.scielo.br/scielo.php? script=sci_ arttext\&pid $=$ S0102-79722004000300003\&lng $=$ pt $\&$ nrm $=$ iso

Rosa, M. (2008). Ser um homem segundo a tradição? Fractal:Revistade Psicologia,20(2). Recuperadoem 3 set. 2009, em http://www.scielo.br/scielo.php?script $=$ sci_ arttext\&pid=S1984-02922008000200010\&lng=pt\& $\mathrm{nrm}=$ iso

Schettini, S. S. M., Amazonas, M. C. L. A., \& Dias, C. M. S. B. (2006). Famílias adotivas: Identidade e diferença. Psicologia em Estudo, 11(2), 285-293. Recuperado em 3 set. 2009, em http://www.scielo.br/scielo.php? script=sci_ arttext\&pid $=$ S1413-73722006000200007\&lng $=$ pt \&nrm $=$ iso

Silva, M. R., \& Piccinini, C. A. (2007). Sentimentos sobre a paternidade e o envolvimento paterno: um estudo qualitativo. Estudos de Psicologia, 24(4). Recuperado em 3 set. 2009, em http://www.scielo.br/ scielo.php?script=sci_arttext\&pid=S0103-166X200 $7000400015 \& \operatorname{lng}=\mathrm{pt \&} \mathrm{nrm}=$ iso 
Tarnowski, K. S., Próspero, E. N. S., \& Elsen, I. (2005). A participação paterna no processo de humanização do nascimento: Uma questão a ser repensada. Texto \& ContextoEnfermagem,14(spe). Recuperadoem 3 set. 2009,emhttp://www.scielo.br/scielo.php?script $=$ sci_ arttext\&pid=S0104-07072005000500013\&lng $=$ pt\& $\mathrm{nrm}=$ iso

Thurler, A. L. (2006). Outros horizontes para a paternidade brasileira no século XXI? Sociedade e Estado, 21(3). Recuperado em 3 set. 2009, em http://www.scielo.br/scielo.php?script $=$ sci_ arttext\&pid=S0102-69922006000300007\&lng =pt $\& n r m=$ iso

Wagner, A., Predebon, J., Mosmann, C., \& Verza, F. (2005). Compartilhar tarefas? Papéis e funções de pai e mãe na família contemporânea. Psicologia: Teoria e Prática, 21(2). Recuperado em 3 set. 2009, em http://www.scielo.br/scielo.php? script $=$ sci_ arttext\&pid=S0102-37722005000200008\&lng $=$ pt $\& n r m=$ iso

Recebido: 19/04/2010

Received: 04/19/2010

Aprovado: 30/06/2010

Approved: 06/30/2010 